\title{
Event-Related Potentials (ERPs) During Repetition Priming in Alzheimer's Patients and Young and Older Controls*
}

\author{
David Friedman ${ }^{1}$, Marla Hamberger ${ }^{2}$, Yaakov Stern ${ }^{3}$, and Karen Marder ${ }^{4}$ \\ New York State Psychiatric Institute ${ }^{1,2}$ \\ and Neurological Institute ${ }^{3,4}$ New York
}

\begin{abstract}
Although memory tested explicitly (e.g., recognition) is clearly deficient in the early stages of Alzheimer's disease, it is less clear if memory tested implicitly is similarly affected. To assess this, event-related potentials (ERPs) were recorded during a word-repetition priming paradigm, with semantic and orthographic orienting tasks, from 10 patients with mild probable Alzheimer's disease (PAD; mean age of 70.6), 10 young (24.1) and 10 older (69.8) controls. The extent of priming by word repetition was assessed using the new minus old ERP repetition effect. The young and older control groups showed clear ERP repetition effects that were larger during semantic than orthographic blocks. Although the PAD patients displayed the same general trends, their ERP repetition effects were not nearly as marked when compared to controls. To the extent that the ERP repetition effect recorded during this repetition priming paradigm is a measure of implicit performance, the data suggest that memory assessed in this fashion is spared in at least some Alzheimer's patients in the early stages of the disease.
\end{abstract}

The results of studies concerned with the memory function of patients with probable Alzheimer's disease (PAD) show uniformly poor performance when the subject is required to consciously retrieve items from memory (e.g., Wilson,

* The authors thank Mr. Charles L. Brown for computer programming and data reduction. We thank Ms. Rachel Yarmolinsky, and Mr. Marvin Nalick for the construction and photo reproduction of figures. This research was supported in part by Grants AG05213, AG07232 and AG8702 from the USPHS, by the New York State Department of Mental Hygiene, and the Charles S. Robertson Memorial Gift for Alzheimer's Disease. The Computer Center at New York State Psychiatric Institute is supported in part by a grant (MH-30906) from the National Institute of Mental Health. Dr. Friedman is supported in part by Research Scientist Development Award \#K02 MH00510. The authors thank Dr. Walter Ritter for reading an earlier draft of this manuscript and for providing helpful critical commentary.

Address requests for reprints and correspondence to Dr. David Friedman, Medical Genetics (A308), New York State Psychiatric Institute, 722 West 168 Street, New York City, NY 10032, USA.

Accepted for publication: July 8, 1991. 
Bacon, Kramer, Fox, \& Kaszniak, 1983). When retention is tested without the requirement of conscious recollection, however, the results do not suggest uniformly poor performance. These two kinds of memory tests have been labelled, respectively, explicit and implicit. Thus, implicit memory is exhibited by an increase in a subject's skill in processing a previously presented stimulus, while explicit memory is demonstrated by a subject's awareness that he encountered that stimulus in a previous episode. The two kinds of memory are thus distinguished by the type of retrieval test. We use the terms implicit and explicit to identify two types of memory test and not theoretical forms of memory, thus avoiding the use of the same terms to refer to a type of test and a type of memory (RichardsonKlavehn \& Bjork, 1988).

It has been repeatedly and powerfully demonstrated that amnesic patients have the ability to benefit from prior exposure to stimulus materials, even though on questioning they have no recollection of having been previously exposed to those same stimuli (cf., Graf \& Mandler, 1984). Since performance on implicit tests of memory appears to be normal in amnesia (whereas memory tested explicitly is markedly deficient), finding a deficit in implicit test performance for PAD patients would suggest that damage to brain systems in addition to those damaged in amnesia occurs at a relatively early stage of the PAD process.

\section{Implicit Performance in PAD}

In one form of implicit test (labelled repetition priming), complete words are presented during a study phase (with instructions, for example, to provide a definition of the presented word). This is followed by a test phase (labelled stem completion), in which those same words' three-letter stems are presented, and subjects are required to produce the "first word that comes to mind." The extent to which the words seen during the study phase are supplied relative to baseline or foil stems is taken as the measure of implicit performance. Such repetition priming is assumed to occur because the first presentation of a word primes or produces activation of the appropriate node in the semantic memory network so that on second presentation the processing of the word is more efficient relative to its first presentation. Using stem completion as the memory test, Partridge, Knight, and Freehan (1990) required their subjects to provide the meaning of words during a study phase and reported normal levels of implicit performance in PAD patients. Similarly, Grosse, Wilson, and Fox (1990) used a sentencecompletion task during study, and reported that their PAD subjects showed equivalent stem-completion performance to controls. By contrast, Salmon, Shimamura, Butters, and Smith (1988) reported that PAD subjects showed impaired stem-completion performance relative to controls after having studied words which they were required to rate for "likeability" (see also, Heindel, Salmon, Shults, Walicke, \& Butters, 1989).

Moscovitch (1982) and Ober and Shenaut (1988) employed a different type of task that also assessed repetition priming. They repeated words within a series of lexical decision trials, and found that their PAD subjects showed normal 
reaction time facilitation to the repeated words (i.e., faster reaction times to the second relative to the first presentation of the word).

In another type of implicit retention test, labelled associative priming, Brandt, Spencer, McSorley, and Folstein (1988) and Huff, Mack, Mahlman and Greenberg (1988) also reported impaired implicit memory performance in PAD patients. Similarly, Heindel, Salmon and Butters (1990) reported that fragment completion performance for pictures that had been previously named was reliably poorer for PAD than for control subjects, again suggesting impaired implicit memory.

In all of the investigations reviewed above, explicit memory for these same words or pictures was markedly impaired in PAD relative to control subjects. However, the results of these studies do not suggest uniform deficits in PAD patients during all tasks assumed to tap implicit memory performance. It appears that some of the variability may be due to differences in the requirements of the orienting task during the study phase, which influences performance on the subsequent implicit task (e.g., Brandt et al., 1988; Nebes, 1989). Further, recent evidence suggests that different implicit tasks tap different underlying processes (Dunn \& Kirsner, 1989) so that performance on a particular task would depend upon a particular patient's pattern of processing deficits.

\section{Implicit Performance in Normally Aging Adults}

Normally aging older adults appear to demonstrate intact implicit retention as measured by repetition priming when assessed via stem-completion performance (e.g., Light \& Singh, 1987), as well as by repetition within a series of lexicaldecision (e.g., Moscovitch, 1982) and semantic decision (e.g., Hamberger \& Friedman, 1990) trials. Similar to PAD patients, the normally aging older adult is usually at a disadvantage relative to young adult controls when explicit retention of these same stimuli is assessed (although the deficit is not nearly as marked as it is for individuals diagnosed with PAD). However, recent data (e.g., Chiarello \& Hoyer, 1988; Davis et al., 1990; Hultsch, Masson, \& Small, 1991) suggest that the elderly may show small, but reliable deficits in implicit retention as well. Moreover, some data implicate slowing in the speed of activation for elderly compared to younger controls (cf., Howard, Shaw, \& Heisey, 1986; but, see Burke, White, \& Diaz, 1987). Since activation is presumed to be responsible for priming to occur (cf., Graf \& Mandler, 1984), slowing of the processes involved in activation might be one mechanism responsible for the relatively poorer performance in older compared to younger adults (see Salthouse, 1988 for a more detailed discussion). As for PAD patients, however, the pattern of spared and relatively impaired implicit performance in the elderly may depend upon several factors, including task instructions and the nature of the retention test (see Light, 1991 for a review).

\section{Event-Related Potentials (ERPs) in Patients with Senile Dementia}

The ERP is one of the few techniques that provides a millisecond by millisecond readout of the brain's processing of information time-locked to stimulus input. 
This continuous readout allows one to view, in real time, the intervening stages of processing between the stimulus and the behavioral response. Moreover, the electrical potentials recorded from the scalp reflect the timing and sequence of neuronal activity underlying cognitive processes (Hillyard \& Picton, 1987). In many instances, a discriminative response is not required to differentiate experimental conditions (e.g., Kutas \& Hillyard, 1989; Rugg, Furda, \& Lorist, 1988), making it a useful measure for studies of patient populations.

The latency of one such scalp-recorded electrical potential, the P300, or P3b, has been related to the time it takes for stimulus evaluation to occur (cf., McCarthy \& Donchin, 1981), and thus would be expected to be delayed in patients with cognitive deficits. Accordingly, the $\mathrm{P} 3 \mathrm{~b}$ has been extensively studied in clinical populations. In their seminal paper, Goodin, Squires, and Starr (1978) reported that demented patients showed P3b latencies substantially longer than age-matched controls. However, Pfefferbaum, Wenegrat, Ford, Roth, and Kopell (1984) and Kraihuin et al. (1990) reported a failure to distinguish mildly demented subjects from controls on the basis of P3b latency. Their data suggest that P3b latency during simple target detection tone paradigms may not be sensitive enough to reflect cognitive impairments in $\mathrm{PAD}$, and argue for employing more ecologically valid tasks with these patients, since diagnostic specificity may be tied to those aspects of cognition that are dysfunctional in PAD. Specifically, implicit and explicit patterns of memory impairment may be a better way of assessing cognitive dysfunction in PAD, and is the focus of the current experiment.

\section{ERP Correlates of Repetition Priming}

The ERP provides complimentary information to that inferred from behavioral measures during the test phases (whether implicit or explicit) of memory experiments. Consistent findings on explicit recognition testing and during repetition priming in an implicit task are that ERPs elicited by the second presentation of an item are more positive than the ERP to its first presentation (the ERP "repetition effect;" see Friedman, 1990 and Rugg et al., 1988, for examples). This repetition effect extends from about 300 to $700 \mathrm{~ms}$ poststimulus.

In pilot studies with PAD patients, we found that it was quite difficult for them to produce explicit, choice old/new reaction time responses (i.e., overt identification that an item had repeated) during a modification of a continuous recognition memory paradigm (Friedman, 1990). However, an advantage of using ERPs is that the repetition effect can be demonstrated without requiring an overt response to indicate an item's previous occurrence (cf., Rugg et al., 1988). Thus, this technique appeared ideally suited to the study of patients with PAD.

Two additional factors led us to employ Rugg's (1987) technique of only repeating frequently occurring, nontarget stimuli that did not require a reaction time response. First, the $\mathrm{P} 3 \mathrm{~b}$ component elicited by stimuli within a class of events is smaller if the class has a high probability of occurrence, despite large variations in the probability of individual items within the class (e.g., Courchesne, Courchesne, \& Hillyard, 1978; Friedman, Ritter, \& Simson, 1978). Thus, using a 
class of stimuli (i.e., nontargets) with a high frequency of occurrence should substantially reduce the amplitude of this component, or eliminate it entirely. Second, requiring a task-relevant decision also elicits the P3b component (see, for examples, Friedman, 1990; Rugg et al., 1988), which typically displays a parietal-maximum scalp distribution. These considerations present two interpretive problems. The repetition effect, which may not be synonymous with the P3b, appears to have a more uniform distribution of amplitudes than $\mathrm{P} 3 \mathrm{~b}$ across the scalp (cf., Rugg et al., 1988; see Friedman, 1990, for a discussion of this issue). Therefore, by requiring a task-relevant reaction time response and/or making repetition a low probability event could have the effect of masking the true nature of the scalp distribution of the repetition effect by the superimposition of a P3b distribution. Moreover, since N400 and P3b overlap to greater or lesser extents in experiments of this nature, and are similarly affected by repetition (i.e., greater positivity or reduced negativity to the repeated item), it would be difficult to determine which component was primarily affected by repetition. For these reasons we embedded the stimuli that repeated within a class of highprobability, nontarget events, and did not include a reaction time measure of repetition priming. Although this results in the lack of a behavioral anchor, a previous study of ours (Hamberger \& Friedman, 1990; in press) demonstrated that the ERP repetition effect was associated with performance enhancement (i.e., decreased reaction time to the repeated item - the typical effect of repetition priming facilitation). Moreover, in lexical decision tasks in which items repeated shortly after their first presentation (within a range of 0 to 29 items in Moscovitch, 1982; within a range of 3 to 30 items in Ober \& Shenaut, 1988), PAD patients in both studies showed the facilitatory effect of repetition priming on reaction time similar to controls.

There are no studies of PAD patients in which ERPs are recorded while implicit memory performance is assessed. In addition, with the exception of our recent study (Hamberger \& Friedman, 1990), this is also true of normally aging adults. Thus, the current study included both young and older controls and was designed to assess implicit measures in PAD patients, and these two control groups using repetition priming and the concurrent recording of ERPs.

\section{METHODS}

\section{Subjects}

There were 15 PAD patients, 11 older controls and 10 young adult controls recruited for this study. The data of five PAD patients and one older control could not be used due to excessive artifact or failure to follow directions. Patients with PAD were diagnosed using NINCDS-ADRDA criteria (McKhann et al., 1984), and an extensive neuropsychological battery, and were required to have had the illness for between 6 months and 3 years at study entrance. Modified Mini-Mental State examination scores (MMS-Mayeux, Stem, Rosen, \& Leventhal, 1981; maximum score $=57$ ) were required to be no lower than 35 (mean for the patient sample was $38.2 ; S D=4.7$ ). Other measures on these patients included computed tomography, complete blood count, serum $\mathrm{B}_{12}$ and hepatic renal and 
thyroid function tests, as well as tests for syphilis and folic acid levels. For the patients all results, except for the Mini-Mental-State scores, were normal.

The 10 young ( 5 females; mean age $=24.1 ; S D=3.4$ ) and 10 older $(8$ females; mean $=$ $69.8, S D=6.3$ ) controls (age-matched to the PAD patients ( 5 females; mean age of 70.6, $S D=9.2$ ) had IQs (greater than 90) and MMS scores within the normal range (50 or better; mean and SD for the young and older controls were, respectively, 56.6, 0.7; and $54.4,2.0$ ). Older controls were free of dementia, depression, and limitation in the activities of daily living as assessed by the Shor CARE (Gurland, Golden, Teresi, \& Challop, 1984).

\section{Stimuli and Procedures}

Four blocks each of semantic (button press to animal word targets) and orthographic (button press to target words presented in uppercase letters) conditions were administered (order of presentation counterbalanced across subjects within each group). Stimuli were presented (duration $=300 \mathrm{~ms}$; ISI $=2 \mathrm{~s}$ ) on a MacIntosh Plus computer. The vertical visual angle subtended by the words was $0.4 \mathrm{deg}$, while the horizontal angles ranged from 1 to $4 \mathrm{deg}$. In each block there were 18 targets to which the subject made a speeded buttonpress response, and 72 nontargets (either nonanimal or lowercase words), which did not require a response. Only nontarget words in each condition were repeated (average lag of 14 items between first and second presentations). Of the 72 nontarget words, 24 were seen only once, and 24 were seen twice. In the data reported below, the comparisons are between first presentation items (i.e., new) and their subsequent repetitions (i.e., old). Thus, new and old items were perfectly balanced with respect to word characteristics (frequency, length, etc.) that could have affected the ERP repetition effect. Only ERPs elicited by correct rejections (i.e., nontargets to which the subject did not respond) are detailed below. Following the 8 blocks, subjects were given 10 minutes to try to recall as many of the words seen during the 8 blocks as possible. This explicit free recall test was unexpected.

\section{Data Acquisition and Recording Procedures}

EEG (.01 to $30 \mathrm{~Hz} ; 5.3 \mathrm{~s}$ time constant), along with vertical (supraorbital to infraorbital bipolar recording) and horizontal (outer canthus of each eye, also bipolar) EOG, was recorded from placements at $\mathrm{Fz}, \mathrm{Cz}, \mathrm{Pz}, \mathrm{F} 3, \mathrm{~F} 4, \mathrm{C} 3, \mathrm{C} 4, \mathrm{~T} 3, \mathrm{~T} 4, \mathrm{P} 3, \mathrm{P} 4, \mathrm{O} 1$, and $\mathrm{O} 2$, all referred to nosetip. Data acquisition and stimulus presentation were under the control of a PDP 11/34 mini-computer, which digitized the physiologic signals at 10-ms intervals for a $300 \mathrm{~ms}$ pre- and a $1700 \mathrm{~ms}$ poststimulus period, and stored the digitized records, along with the subject's reaction time responses, on 9-track digital tape. Trials containing EOG artifact, defined as voltages in excess of $100 \mu \mathrm{V}$, were excluded from the averages. Prior to computing averaged voltage measures of ERP activity, the individual averages were filtered at $15 \mathrm{~Hz}$ using the low-pass filter described by Ruchkin and Glaser (1978).

\section{RESULTS}

Only effects reaching the .05 level of significance after application of the Greenhouse-Geisser correction of degrees of freedom (where appropriate) are reported below (cf., Jennings \& Wood, 1976). In the presence of significant interactions, tests for simple effects (Winer, 1971) were used to further elucidate the findings. Where appropriate, the Tukey honestly significant difference procedure was used to assess significance of differences between means (Winer, 1971). 


\section{Behavioral Data}

As can be seen in Table 1, and as assessed by Diagnostic Group (Young, Older, PAD) by Condition (Semantic, Orthographic) ANOVAs, the main effect of Diagnostic Group on percent target detections was significant $(F(2 / 27)=19.02$, $p<.00001$ ). Post hoc tests indicated that the young and older controls (who did not differ) were more accurate than the PAD patients in detecting target items. Accuracy was greater for all groups in orthographic than semantic blocks $(F(1 / 27)$ $=6.60, p<.02$ ), and the interaction of Diagnostic Group and Condition was not significant. As shown in table 1, the main effect of Diagnostic Group on percentage of false alarms $(F(2 / 27)=8.56, p<.0013)$ indicated, as assessed by post hoc tests, that PAD patients produced a larger number of false alarms than either the young or older controls, who did not differ. The main effect of Condition and the interaction of Condition and Diagnostic Group on the percentage of false alarms were not significant.

For reaction time there was a main effect of Diagnostic Group $(F(2 / 27)=6.44$, $p<.005$ ). Post hoc tests indicated that, although the data were ordered Young < Older < PAD (see Table 1), only the PAD patients differed significantly from the two other groups. Semantic reaction times were longer than orthographic reaction times $(F(1 / 27)=94.20, p<.00001)$, and the interaction of Diagnostic Group and Condition was not significant.

As expected, there was a main effect of Diagnostic Group on the measure of free recall $(F(2 / 25)=18.25, p<.00001)$. Post hoc tests revealed that the PAD patients were markedly impaired relative to both the young and older controls, who did not differ.

Table 1. Behavioral Data for the 3 Samples.

\begin{tabular}{lrrrrrrr}
\hline Group: & $\begin{array}{c}\text { Variable: } \\
\text { Free Rec }\end{array}$ & \% Seman & \% FA & \% Orth & \% FA & RT Seman & RT Orth \\
\hline Young & & & & & & & \\
Mean & 20.9 & 96.8 & .003 & 99.8 & .001 & 673.2 & 548.3 \\
SD & 6.3 & 4.5 & .004 & 4.3 & .002 & 87.8 & 96.6 \\
Older & & & & & & & \\
Mean & 16.8 & 92.8 & .006 & 99.3 & .005 & 770.9 & 608.1 \\
SD & 9.5 & 11.4 & .008 & 1.1 & .010 & 120.2 & 54.4 \\
PAD & & & & & & & \\
Mean & 1.8 & 76.5 & .050 & 85.7 & .090 & 864.7 & 689.5 \\
SD & 1.9 & 7.5 & .054 & 17.5 & .110 & 213.2 & 142.2 \\
\hline
\end{tabular}

FreeRec $=$ total number of items freely recalled; Due to fatigue, the free recall data for 2 PAD patients could not be obtained; Seman = Semantic Condition; Orth = Orthographic Condition; \% Seman = mean percent of correctly detected animal targets; $\%$ Orth $=$ mean percent of correctly detected uppercase targets; $\% \mathrm{FA}=$ percentage of false alarms; RT = reaction time to targets. 


\section{ERP Data}

Figure 1 presents the grand mean ERPs for both orthographic and semantic conditions averaged across subjects within each diagnostic group. For both the young and elderly controls, the ERP repetition effect (old ERP more positive than new ERP) is markedly larger in the semantic than in the orthographic condition, where it appears to be negligible (the exception is for the older controls at the frontal electrodes). As can be seen, the repetition effect during semantic blocks onsets at about $250 \mathrm{~ms}$ in the young controls, but appears to onset somewhat later and have a longer duration in both the older controls' and the PAD subjects' ERPs. As can also be seen, the repetition effect elicited during semantic blocks has a fairly widespread distribution across the scalp in all three groups. Although the between-condition differences in the repetition effect are similar for PAD subjects, their ERPs show smaller repetition effects during the semantic condition than the ERPs of the young and older controls.

The ERPs were quantified as 17 poststimulus bins consisting of $100 \mathrm{~ms}$ of averaged voltage (relative to the $300-\mathrm{ms}$ prestimulus baseline). Additional sum-

YOUNG

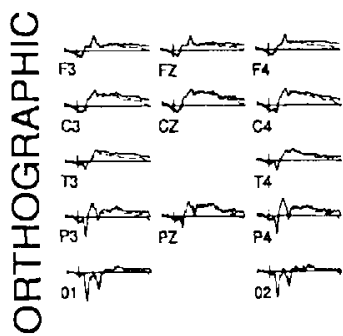

昼

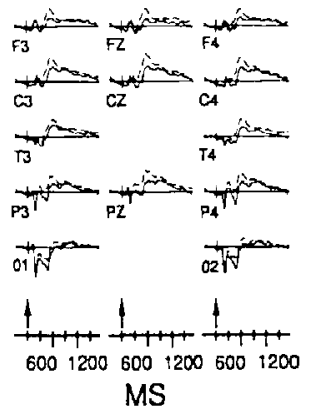

OLDER
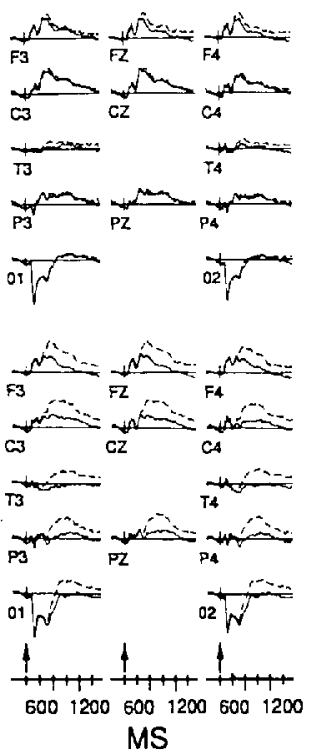

ALZHEIMER
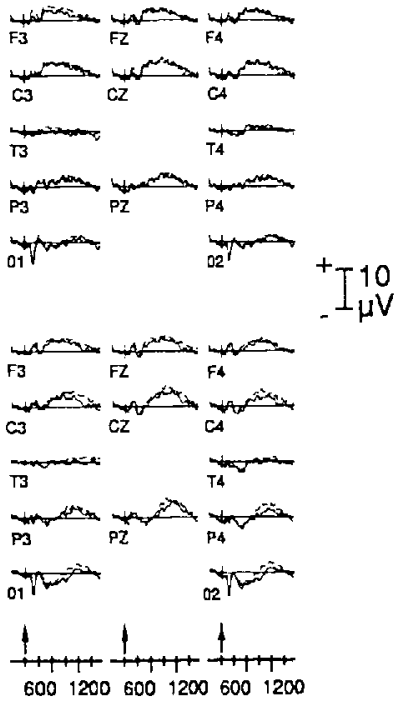

MS.

Fig. 1. Grand mean ERPs, averaged across subjects within each group, elicited by first (new) and second (old) presentations of words seen during orthographic (top) and semantic (bottom) conditions. Vertical hash marks and arrows indicate stimulus onset, with time lines every $300 \mathrm{~ms}$. 
mary measures, consisting of $300 \mathrm{~ms}$ of averaged ERP activity (from 300-600 and 700-1000 ms poststimulus) were computed on the difference means (new minus old ERPs), separately for each condition. These were then averaged across the 3 midline, and the 5 left- and right-hemisphere electrodes to yield mean midline, left- and right-hemisphere summary difference scores. For the 100-ms averaged voltages, Between-Diagnostic Group ANOVAs with repeated measures of Condition and Repetition (New/Old) were performed on the 7 poststimulus bins (representing activity from 300 to $1000 \mathrm{~ms}$ ). These were performed separately at $\mathrm{Fz}, \mathrm{Cz}, \mathrm{Pz}, \mathrm{O} 1$ and $\mathrm{O} 2$ where the effects seemed greatest. Effects on the summary difference scores were assessed via ANOVAs in which the repetition factor (i.e., New vs. Old) was not relevant.

The visual impressions described above (Figure 1) were supported by the ANOVAs of the unsubtracted poststimulus bins. There were main effects of Repetition $(F \mathrm{~s}(1 / 27)>6.86, p \mathrm{~s}<.01$ or less), which were modulated by Condition by Repetition $(F \mathrm{~s}(1 / 27)>5.96, p s<.02$ or less), and Repetition by Group $(F \mathrm{~s}(2 / 27)=4.17, p s<.03$ or less) interactions (these latter interactions occurred only at the $\mathrm{Fz}$ electrode site). The Repetition by Group interactions at Fz were accounted for primarily by the older controls, since tests for simple effects suggested that they showed larger repetition effects (collapsed across conditions) than the young or PAD subjects. More importantly, tests for simple effects of the Condition by Repetition interactions showed that for the semantic condition the effect of repetition was highly significant $(F \mathrm{~s}(1 / 27)>10.41, p \mathrm{~s}<.003$ or less $)$, with the majority of bins at all 5 electrode sites producing significant effects. By contrast, of $35 F$ tests performed for the orthographic condition ( 7 bins between 300 and $1000 \mathrm{~ms}$ for 5 electrode sites), only two $(600-700 \mathrm{~ms}: F(1 / 27)=5.80, p$ $<.02$; and 700-800 ms: $F(1 / 27)=4.86, p<.04)$, restricted to $F z$, showed main effects of Repetition. Moreover, the effect at $600-700 \mathrm{~ms}$ was modulated by a Repetition by Diagnostic Group interaction $(F(2 / 27)=3.38, p<.05)$. Post hoc tests indicated that only the older controls showed a significant repetition effect during orthographic blocks at Fz.

There were also significant Condition by Group interactions at $\mathrm{O} 1$ and $\mathrm{O} 2$ only $\left(F_{\mathrm{S}}(2 / 27)>3.94, p s<.03\right.$ or less $)$. Tests for simple effects of these interactions suggested that, although all groups' semantic ERPs were more negative than their orthographic counterparts from about $400-700 \mathrm{~ms}$ (at $\mathrm{O} 1$ and $\mathrm{O} 2$; see Figure 1), these condition differences were greater for the older controls and PAD patients: Of greater interest, however, was the fact that there were no significant Group by Condition by Repetition interactions at any electrode site for these measures.

To summarize, the repetition effect was markedly larger from about 300 to $1000 \mathrm{~ms}$ poststimulus in the semantic than in the orthographic condition, where it was restricted to $\mathrm{Fz}$ and was significant only in the ERPs of the older controls. Although the PAD subjects' repetition effect was smaller than that seen in either the young or older control groups, the same general Repetition and Condition effects were seen in their ERPs. 
ANOVAs of the midline new-old summary scores corroborated the results detailed above. For the $300-600 \mathrm{~ms}(F(1 / 27)=7.79, p<.009)$ and $700-1000 \mathrm{~ms}$ $(F(1 / 27)>6.10, p<.003)$ measures there was a main effect of Condition, indicating that semantic blocks produced a greater new-old difference than orthographic blocks. Only the 700-1000 ms measure produced a significant effect of Diagnostic Group $(F(2 / 27)=4.42, p<.02)$. Post hoc tests showed that the older controls produced a greater new-old difference than either the PAD or young subjects, who did not differ from each other. This was primarily due to the fact that the young adults showed an earlier onset and shorter duration repetition effect, that was decrementing during the 700-1000 ms time window (see Figure 1). For neither measure was the Condition by Group interaction significant.

ANOVAs performed on the lateral electrode summary measures showed that the new-old difference (measured from $300-600 \mathrm{~ms}$ poststimulus) was larger over the right than the left hemisphere $(F(1 / 27)=18.16, p<.0002)$, without a Diagnostic Group by Hemisphere interaction. Neither the main effect of Hemisphere nor the interaction of Hemisphere and Diagnostic Group were significant for the $700-1000 \mathrm{~ms}$ summary score.

The amplitude of the repetition effect (as indexed by the midline 300-600 and 700-1000 ms summary measures) was not significantly correlated with either the MMS score or the percentage of correctly detected targets. By contrast, the total number of words recalled was highly correlated with MMS score $(0.78, p<.01)$.

To visualize the degree of ERP repetition priming for individual subjects within each group, Figure 2 presents the midline summary difference score measures

\section{POST-STIMULUS PERIOD}

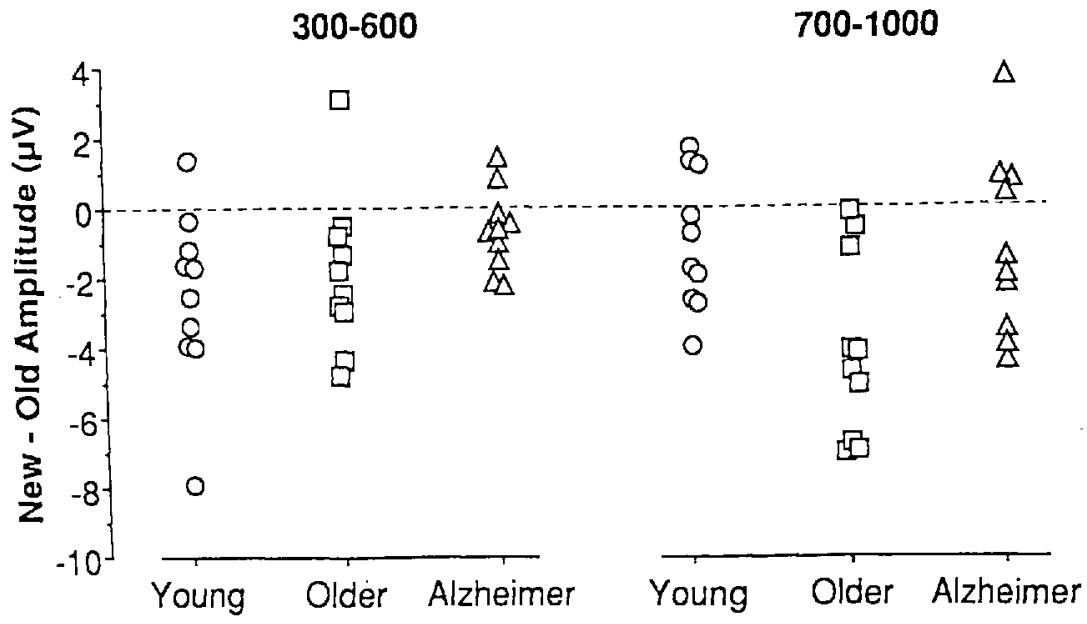

Fig. 2: Individual midline summary scores in the semantic condition for the 300-600 and $700-1000$ ms periods of ERP activity. 
in the semantic condition for the 300-600 and 700-1000 msec scores of averaged new-old activity for each of the 30 participants. As can be seen, the PAD group shows more subjects above the zero point, indicating that the repeated item produced less positivity (or greater negativity) than the new item. As can also be seen, the magnitude of the new-old effect depends upon the time period. For the 300-600 ms period, the young and older controls show similar magnitude repetition effects, with the PAD subjects clustered around zero. For the $700-1000 \mathrm{~ms}$ period, by contrast, the older controls show the greatest magnitudes (due to the fact that their repetition effect showed a later onset and longer duration), while approximately 6 PAD subjects show the effect in the same direction as controls, with 4 producing the opposite effect. For the latter subjects, this might indicate something akin to what could be termed "negative priming" in the behavioral literature see discussion of Albert and Milberg's, (1989) data below - although the extent to which the ERP and behavioral effects share similar underlying processes is not known at this time.

\section{DISCUSSION}

Although the PAD group produced fewer correct target detections and longer reaction times than either the young or older controls in both tasks, the fact that they showed the same between-task differences as control subjects suggests that the processing of PAD subjects can be directed by the appropriate encoding task.

The greater positivity to the repeated item may reflect the increased efficiency (due to activation by the first presentation) in processing the second presentation of the word (i.e., priming). Thus, the data suggest that at least some PAD subjects show the repetition effect and that it might be used as an index of priming. The lack of correlation of this measure with severity of dementia (as indexed by the MMS) suggests that the ERP repetition effect reflects a relatively automatic process by contrast with the measure of free recall which showed a substantial correlation with MMS (see Hasher \& Zacks, 1979).

The current data suggest that the new-old difference might be synonymous with the N400 component recorded during sentence congruity (e.g., Kutas \& Hillyard, 1980a) and semantic priming (e.g., Bentin, McCarthy, \& Wood, 1985) paradigms. In keeping with this tentative conclusion, the new-old difference (between 300 and $600 \mathrm{~ms}$ poststimulus) was larger over the right hemisphere for all groups of subjects, similar to reports for N400 (e.g., Kutas \& Hillyard, 1980b). Moreover, consistent with the N400 data from other laboratories (e.g., Kutas \& Hillyard, 1989; Rugg et al., 1988), our results also suggest that the ERP correlate of priming can be observed in the absence of task relevant responses to the primed item.

The current findings suggest that the ERP repetition effect reflects the brain's identification of the occurrence of a previous event during a task in which the subject's attention is directed away from the overt detection of such repetition. 
The data also suggest that memory measured in this fashion, i.e., as reflected by the ERP repetition effect, is spared in at least some PAD patients in the early stages of the disease. Moreover, since the ERP differentiated first from second presentation primarily during semantic blocks, word presentation may not automatically induce access to word meaning if it is not required to perform the task, suggesting that the word repetition effect is dependent upon the level of processing required by the task (see also Deacon, Breton, Ritter, \& Vaughan, 1991; Rugg et al., 1988). As indicated by a lack of Group by Condition by Repetition interactions in any of the analyses detailed above, and in keeping with the interpretation just offered, the ERP as well as the performance data also suggest that the PAD patients processed the words to meaning during semantic blocks.

Similarly, the data argue for the conclusion that implicit retention, as indexed by the ERP repetition effect, is intact in the normal elderly, supporting previous findings (e.g., Light \& Singh, 1987). However, relative to young adult controls, the repetition effect of the older control subjects showed delayed onset and longer duration. To the extent that this ERP effect reflects automatic activation (when subjects direct attention to semantic processing of words), the data suggest that the elderly control group may differ in the speed and duration of such activation, supporting recent behavioral findings (cf., Howard et al., 1986).

These data are similar to the data of others who, in purely behavioral tasks, reported evidence of repetition priming in PAD (e.g., Moscovitch, 1982; Ober \& Shenaut, 1988). They are also similar to previous results in which not all subjects within the Alzheimer sample showed evidence of priming or "implicit" memory. For example, Knopman and Nissen (1987) reported that of 28 PAD patients in their sample, 19 showed intact implicit memory for procedural knowledge while 9 did not. These two groups could not be distinguished on the basis of severity of dementia or age, but the 9 PAD subjects who showed no evidence of implicit learning did score lower on selected tests of nonverbal reasoning. Similarly, in a lexical decision task (Albert \& Milberg, 1989), 6 of 10 PAD subjects showed semantic facilitation (i.e., reaction time was faster to related than unrelated primes), while 4 of them showed negative priming (i.e., reaction time was faster to the unrelated than the related primes). In another study by Huff et al: (1988), only 3 of 8 PAD subjects showed evidence of associative priming.

In further support of these reports of variability in the performance of PAD patients are reports of variability in clinical symptomatology and affected brain areas in PAD (e.g., Jagust, Davies, Tiller-Borcich, \& Reed, 1990; Pfefferbaum et al., 1990). Taken in conjunction with these reports, the current data support the conclusions of variability in performance with an ERP measure. Therefore, one potentially fruitful avenue of research might be to attempt to determine if there are any characteristics that distinguish those PAD patients exhibiting the ERP repetition priming effect from those who do not. 


\section{REFERENCES}

Albert, M., \& Milberg, W. (1989). Semantic processing in patients with Alzheimer's disease. Brain and Language, 37, 163-171.

Bentin, S., McCarthy, G., \& Wood, C.C. (1985). Event-related potentials, lexical decision and semantic priming. Electroencephalography and Clinical Neurophysiology, 60,343355.

Brandt, J., Spencer, M. McSorley, P., \& Folstein, M.F. (1988). Semantic activation and implicit memory in Alzheimer's disease. Alzheimer's Disease and Associated Disorders, 2, 112-119.

Burke, D.M., White, H., \& Diaz, D.L. (1987). Semantic priming in young and older adults: Evidence for age constancy in automatic and attentional processes. Journal of Experimental Psychology: Human Perception and Performance, 13, 79-88.

Chiarello C., \& Hoyer, W.J. (1988). Adult age differences in implicit and explicit memory: Time course and encoding effects. Psychology and Aging, 3, 358-366.

Courchesne, E., Courchesne, R.Y., \& Hillyard, S.A. (1978). The effect of stimulus deviation on P3 waves to easily recognized stimuli. Neuropsychologia, 16, 189-199.

Davis, H.P., Cohen, A., Gandy, M., Colombo, G., VanDusseldorp, G., Simolke, N., \& Romano, J. (1990). Lexical priming deficits as a function of age. Behavioral Neuroscience, 104, 288-297.

Deacon, D., Breton, F., Ritter, W., \& Vaughan, H.G., Jr. (1991). The relationship between N2 and N400: Scalp distribution, stimulus probability and task relevance. Psychophysiology, 28, 185-200.

Dunn, J.C., \& Kirsner, K. (1989). Implicit memory: Task or process? In S. Lewandowsky, J.C. Dunn, \& K. Kirsner (Eds.), Implicit memory: Theoretical issues (pp. 17-31). Hillsdale: Lawrence Erlbaum Associates,

Friedman, D. (1990). Endogenous brain potentials during continuous recognition for words. Biological Psychology, 30, 61-87.

Friedman, D., Ritter, W., \& Simson, R. (1978) Analysis of non-signal evoked cortical potentials in two kinds of vigilance tasks. In D. Otto (Ed.), Multidisciplinary per. spectives in event-related brain potential research (pp. 194-197). Washington, DC: U.S. Government Printing Office.

Goodin, D.S., Squires, K.C., \& Starr', A. (1978). Long latency event-related components of the auditory evoked potential in dementia, Brain, 101, 635-648.

Graf, P., \& Mandler, G. (1984). Activation makes words more accessible, but not necessarily more retrievable. Journal of Verbal Learning and Verbal Behavior, 23, 553-568.

Grosse, D.A., Wilson, R.S., \& Fox, J.H. (1990). Preserved word-stem- completion priming of semantically encoded information in Alzheimer's disease. Psychology and Aging, 5, 304-306.

Gurland, B., Golden, R.R., Teresi, J.A., \& Challop, J. (1984). The SHORT CARE: An efficient instrument for the assessment of depression, dementia and disability. Journal of Gerontology, 39, 166-169.

Hamberger, M., \& Friedman, D. (1990). Age-related changes in semantic activation: Evidence from event-related potentials. In C.H.M. Brunia, A.W.K. Gaillard, \& A. Kok (Eds.), Psychophysiological brain research (pp. 279-284). Tilburg: Tilburg University Press.

Hamberger, M., \& Friedman, D. (in press). ERP correlates of repetition priming and stimulus classification in young and older adults. Journals of Gerontology: Psycho. logical Sciences.

Hasher, L., \& Zacks, J.T. (1979). Automatic and effortful processes in memory. Journal of Experimental Psychology: General, 108, 356-388.

Heindel, W.C., Salmon, D.P., \& Butters, N. (1990). Pictorial priming and cued recall in Alzheimer's disease and Huntington's disease. Brain and Cognition, 13, 282-295. 
Heindel, W.C., Salmon, D.P., Shults, C.W., Walicke, P.A., \& Butters, N. (1989). Neuropsychological evidence for multiple implicit memory systems: A comparison of Alzheimer's, Huntington's, and Parkinson's disease patients. Journal of Neuroscience, 9, 582-587.

Hillyard, S.A., \& Picton, T.W. (1987). Electrophysiology of cognition. In V.B. Mountcastle, F. Plum, \& S.R. Geiger (Eds.), Handbook of Physiology. Vol. V: Higher functions of the brain, Part 2, (pp. 519-583). Baltimore: American Physiological Society.

Howard, D.V., Shaw, R.J., \& Heisey, J.G. (1986). Aging and the time course of semantic activation. Journal of Gerontology, 41, 195-203.

Huff, F.J., Mack, L., Mahlmann, J., \& Greenberg, S. (1988). A comparison of lexicalsemantic impairments in left hemisphere stroke and Alzheimer's disease. Brain and Language, 34, 262-278.

Hultsch, D.F., Masson, M.E.J., \& Small, B.J. (1991). Adult age differences in direct and indirect tests of memory. Journal of Gerontology: Psychological Sciences, 46, P22-30. Jennings, J.R., \& Wood, C.C. (1976). The E-adjustment procedure for repeated-measures analyses of variance. Psychophysiology, 13, 277-278.

Jagust, W.J., Davies, P., Tiller-Borcich, J.K., \& Reed, B.R. (1990). Focal Alzheimer's disease. Neurology, 40, 14-19.

Knopman, D.S., \& Nissen, M.J. (1987). Implicit leaming in patients with probable Alzheimer's disease. Neurology, 37, 784-788.

Kraiuhin, C., Gordon, E., Coyle, S., Sara, G., Rennie, C., Howson, A., Landau, P., \& Meares, R. (1990). Normal latency of P300 event-related potential in mild-to-moderate Alzheimer's disease and depression. Biological Psychiatry, 28, 372-386.

Kutas, M., \& Hillyard, S.A. (1980a). Reading senseless sentences: Brain potentials reflect semantic incongruity. Science, 207, 203-205.

Kutas, M., \& Hillyard (1980b). Reading between the lines: Event- related brain potentials during natural sentence processing. Brain and Language, 11, 354-373.

Kutas, M., \& Hillyard, S.A. (1989). An electrophysiological probe of incidental semantic association. Journal of Cognitive Neuroscience, 1, 38-49.

Light, L.L. (1991). Memory and aging: Four hypotheses in search of data. Annual Review of Psychology, 42, 333-376.

Light, L.L., \& Singh, A. (1987). Implicit and explicit memory in young and older adults. Journal of Experimental Psychology: Learning, Memory and Cognition, 13, 531-541.

Mayeux, R., Stem, Y., Rosen, J., \& Leventhal, J. (1981). Depression, intellectual impairment and Parkinson's disease. Neurology, 31, 645-650.

McCarthy, G., \& Donchin, E. (1981). A metric for thought: A comparison of P300 latency and reaction time. Science, $211,77-80$.

McKharn, G., Drachman, D., Folstein, M., Katzman, R., Price, D., \& Stadian, E.M. (1984). Clinical diagnosis of Alzheimer's disease: Report of the NINCDS-ADRDA Work Group under the auspices of Department of Health and Human Services Task Force on Alzheimer's disease. Neurology, 34, 939-944.

Moscovitch, M. (1982). A neuropsychological approach to perception and memory in normal and pathological aging. In F.I.M. Craik \& S. Trehub (Eds.), Aging and cognitive processes, (pp. 55-78). New York: Plenum Press.

Nebes, R.D. (1989). Semantic memory in Alzheimer's disease. Psychological Bulletin, 106, 377-394.

Ober, B.A., \& Shenaut, G.K. (1988). Lexical decision and priming in Alzheimer's Discase. Neuropsychologia, 26, 273-286.

Partridge, F.M., Knight, R.G., \& Feehan, M. (1990). Direct and indirect memory performance in patients with senile dementia. Psychological Medicine, 20, 111-118.

Pfefferbaum, A., Sullivan, E.V., Jemigan, T.L. Zipursky, R.B., Rosenbloom, M.J., Yesavage, J.A., \& Tinkleberg, J.R. (1990). A quantitative analysis of CT and cognitive measures 
in normal aging and Alzheimer's disease. Psychiatry Research: Neuroimaging, 35, 115136.

Pfefferbaum, A., Wenegrat, B., Ford, J.M., Roth, W.T., \& Kopell, B.S. (1984). Clinical application of the P3 component of event-related potentials II. Dementia, depression and schizophrenia. Electroencephalography and Clinical Neurophysiology, 59, 104-124. Richardson-Klavehn, A., \& Bjork, R.A. (1988). Measures of memory. Annual Review of Psychology (pp. 475-543). New York: Annual Reviews.

Ruchkin, D.S., \& Glaser, E.M. (1978). Simple digital filters for examining CNV and P300 on a single-trial basis. In D. Otto, (Ed.), Multidisciplinary perspectives in event-related brain potential research (pp. 579-581). Washington, DC: U.S. Govt Print. Office, EPA-600/9-77-043.

Rugg, M.D. (1987). Dissociation of semantic priming, word and non-word repetition effects by event-related potentials. Quarterly Journal of Experimental Psychology. 39A, 123-148.

Rugg, M., Furda, J., \& Lorist, M. (1988). The effects of task on the modulation of eventrelated potentials by word repetition. Psychophysiology, 25, 55-63.

Salmon, D.P., Shimamura, A.P., Butters, N., \& Smith, S. (1988). Lexical and semantic priming deficits in patients with Alzheimer's disease. Journal of Clinical and Experimental Neuropsychology, 10, 477-494.

Salthouse, T.A. (1988). Initiating the formalization of theories of cognitive aging. Psychology and Aging , 3, 3-16.

Wilson, R.S., Bacon, L.D., Kramer, R.L., Fox, J.H., \& Kaszniak, A.W., (1983). Word frequency effect and recognition memory in dementia of the Alzheimer type., Journa! of Clinical Neuropsychology, 5, 97-104.

Winer, B.J. (1971). Statistical principles in experimental design. New York: McGraw Hill. 